\title{
Rapid Determination of Antibiotic Susceptibility by Stimulated Raman Scattering Imaging of $\mathrm{D}_{2} \mathrm{O}$ Metabolism
}

\author{
Weili Hong, ${ }^{\dagger} \mathrm{Ji}-\mathrm{Xin}$ Cheng**,s \\ $\dagger$ Beijing Advanced Innovation Center for Biomedical Engineering, School of Biological Science and Medical Engineering, \\ Beihang University, Beijing 100083, China \\ ‡ Department of Electrical \& Computer Engineering, ${ }^{\S}$ Department of Biomedical Engineering, Boston University, Boston, \\ Massachusetts 02215, United States
}

\begin{abstract}
Rapid antibiotic susceptibility testing (AST) is urgently needed for treating infections with correct antibiotics and slowing down the emergence of antibiotic resistant bacteria. Current clinical methods reply on culture and take at least $16 \mathrm{~h}$. Here, using $P$. aeruginosa, E. coli and $S$. aureus as models, we show that the AST can be finished in 10 minutes by stimulated Raman scattering (SRS) imaging of $\mathrm{D}_{2} \mathrm{O}$ metabolic activities. The metabolic incorporation of $\mathrm{D}_{2} \mathrm{O}$, which is used for biomolecule synthesis, can be monitored in a single bacterium. Time lapse experiments show that the $\mathrm{C}$-D vibrational signal can be observed in a single bacterium within 10 minutes culture in $\mathrm{D}_{2} \mathrm{O}$ medium. Since water is universally used for biosynthesis in bacteria, SRS imaging of $\mathrm{D}_{2} \mathrm{O}$ metabolism has the potential to be generalizable to different bacteria species.
\end{abstract}

Antimicrobial resistance has become a growing public threat, causing nearly 1 million deaths from drug-resistant infections each year globally ${ }^{1}$. It was estimated that by 2050 , antimicrob ial resistance will cause 10 million deaths and \$100 trillion GDP loss if no action is taken ${ }^{1,2}$. To combat this crisis, new rapid diagnostic methods for antibiotic susceptibility testing (AST) are essential to reduce the deaths caused by drug-resistant infections $^{3}$, and slow down the emergence of antimicrobial resistance. The culture-based phenotypic method remains the gold standard for AST. However, this method is too slow for guidance of immediate decision for infectious disease treatment. Genotypic methods, which detect known resistance genes, can provide faster results, but are not generally applicable to different bacteria and mechanism of resistance ${ }^{4}$.

To overcome these limitations, other methods have been developed for rapid AST, including, for example, microfluid ic devices that increase the detection sensitivity by confining the sample in a small area ${ }^{5-10}$, imaging-based methods that monitor the growth or morphology change at the single cell level ${ }^{10-12}$, nucleic acids-based phenotypic AST quantifying nucleic acids copy number with antibiotic treatment ${ }^{4,13,14}$, and monitoring the spectral response to antibiotic treatment by Raman spectroscopy ${ }^{15}$. While these methods significantly reduce the time for AST, they either are not generalizable to different bacteria, or rely on cell proliferation, which has difficulties for viable but nonculturable species $^{16}$, or require gene marker information before testing ${ }^{17}$.

We have previously demonstrated that the AST of bacteria can be accomplished within one cell cycle (30 minutes) by measuring the metabolic activity in single bacteria under a stimulated Raman scattering (SRS) microscope ${ }^{18}$. Specifically, we monitored the metabolic activity of deuterated glucose, glucose- $\mathrm{d}_{7}$, with chirped picosecond SRS at C-D vibrational frequency and used the C-D signal as a marker to perform AST. Like glucose, water is also ubiquitously used for biomolecule synthesis in bacteria ${ }^{19}$, and its metabolism can be selectively probed via monitoring the conversion of heavy water $\left(\mathrm{D}_{2} \mathrm{O}\right)$ into deuterated biomolecules at $\mathrm{C}$-D vibrational frequency. Unlike glucose- $\mathrm{d}_{7}, \mathrm{D}_{2} \mathrm{O}$ itself does not have C-D bonds, therefore providing a better contrast for SRS metabolic imaging. The metabolic activity of $\mathrm{D}_{2} \mathrm{O}$ has been used to study the metabolicactive bacteria with spontaneous Raman spectroscopy ${ }^{16,19}$. However, the speed of spontaneous Raman is limited by the weak Raman scattering process ${ }^{20}$. Compared to spontaneous Raman, SRS has orders-of-magnitude signal enhancement, thereby enabling high speed chemical imaging of single cells ${ }^{21}$ ${ }^{26}$. SRS imaging of $\mathrm{D}_{2} \mathrm{O}$ metabolism was recently demonstrated to be a noninvasive method to visualize metabolic dynamics in mammalian cells and live animals ${ }^{27}$.

Here, we demonstrate that femtosecond SRS imaging of $\mathrm{D}_{2} \mathrm{O}$ metabolism can determine the susceptibility of bacteria within 10 minutes. We show that the metabolic activity of $\mathrm{D}_{2} \mathrm{O}$ can be monitored in single P. aeruginosa, E. coli and S. aureus. For the broad C-D vibrational spectrum, the SRS signal of bacteria can be improved by more than 5 times by femtosecond SRS compared to the chirped SRS. The $\mathrm{D}_{2} \mathrm{O}$ metabolism in bacteria responds differently as fast as 10 minutes to different antibiotics, depending on the susceptibility of bacteria. Our work shows the promise of using SRS microscopy for metabolic activity studies and rapid AST at single bacterium level.

\section{Experimental Section}

SRS microscope. A femtosecond (fs) pulsed laser (InSight DeepSee, Spectra-Physics) with an 80-MHz repetition rate and dual outputs was employed for the SRS microscope. One 120 fs laser with tunable $680-1100 \mathrm{~nm}$ wavelength was served as the pump beam. The other $220 \mathrm{fs}$ laser centered at $1040 \mathrm{~nm}$, served as the Stokes beam, was modulated by an acoustooptical modulator (AOM, 1205-C, Isomet) at $\sim 2.4 \mathrm{MHz}$. The 
two beams were collinearly combined through a dichroic mirror. When spectral focusing is needed for hyperspectral SRS, both beams were chirped with two $15 \mathrm{~cm}$ long SF57 glass rods. After chirping, the pulse durations of the pump and Stokes laser were $1.9 \mathrm{ps}$ and $1.3 \mathrm{ps}$, respectively. For implementation of SRS imaging with femtosecond pulses, the glass rods were removed from the path. The pump and Stokes beams were directed into a lab-built laser scanning microscope. A 60x water objective (NA=1.2, UPlanApo/IR, Olympus) was used to focus the lasers to the sample, and an oil condenser $(\mathrm{NA}=1.4, \mathrm{U}-\mathrm{AAC}$, Olympus) was used to collect the signal from the sample. Two filters (HQ825/150m, Chroma) were used to filter out the Stokes beam, the pump beam was detected by a photodiode (S3994-01, Hamamatsu) and the stimulated Raman signal was extracted by a lock-in amplifier (HF2LI, Zurich Instrument).

Sample preparation. To make $\mathrm{D}_{2} \mathrm{O}$ containing $\mathrm{LB}$ medium, $\mathrm{D}_{2} \mathrm{O}$ was first mixed with purified water, then LB broth powder (Sigma Aldrich) was added to the solution with a final concentration of $2 \%$ in weight. The solution was sterilized by filtering. To prepare bacteria samples, E. coli, S. aureus or $P$. aeruginosa were cultivated in normal LB medium for $2-3 \mathrm{~h}$ to reach to log phase, then bacteria were diluted in a 1:100 ratio to the $\mathrm{D}_{2} \mathrm{O}$ containing $\mathrm{LB}$ medium. After incubation for a controlled period, $500 \mu \mathrm{l}$ sample was centrifuged, washed twice with purified water, and deposited to an agarose gel pad.

To prepare the agarose gel pad, $\sim 1 \%$ in weight agarose powder was added to $5 \mathrm{ml}$ purified water in a plastic tube, then the tube was heated in microwave for about 20 seconds to melt the agarose powder. About $10 \mu \mathrm{l}$ heated agarose gel solution was added to a coverglass by a pipette, another coverglass was immediately put on the top of the agarose gel solution to make it flat. After $\sim 2 \mathrm{~min}$, one coverglass was removed from the agarose gel by sliding the two coverglasses. Bacteria in solution were deposited to the gel pad, then another coverglass was put on top of the gel pad for SRS imaging.

SRS imaging. To image bacteria at the C-Dregion, the pump wavelength was tuned to $849 \mathrm{~nm}$, and the power at the sample was $\sim 12 \mathrm{~mW}$; the Stokes wavelength was fixed at $1040 \mathrm{~nm}$, and the power at the sample was $\sim 90 \mathrm{~mW}$. Each image contains 200 $\times 200$ pixels, the pixel dwell time is $30 \mu$ s.

Spontaneous Raman spectroscopy. Bacteria in solution were deposited on a coverglass for spontaneous Raman measurement. Spontaneous Raman spectra of bacteria were acquired with an inverted Raman spectrometer (LabRAM HR evolution, Horiba scientific) with $532 \mathrm{~nm}$ laser source. The laser power at the sample was $\sim 12 \mathrm{~mW}$ after $40 \mathrm{x}$ air objective, the acqusition time was $10 \mathrm{~s}$. The grating was $600 \mathrm{l} / \mathrm{mm}$.

Broth dilution method. Bacteria were cultured in $\mathrm{D}_{2} \mathrm{O}$ containing LB medium in a 96-well plate. Antibiotics, using triplicate samples, were added to the plate and serially diluted. After about $20 \mathrm{~h}$ incubation at $37{ }^{\circ} \mathrm{C}$, plates were visually inspected, and the MIC was categorized as the concentration at which no visible growth of bacteria was observed.

\section{Results and Discussion}

$\mathrm{D}_{2} \mathrm{O}$ induces negligible toxicity to bacteria. We first tested whether $\mathrm{D}_{2} \mathrm{O}$ has toxicity to bacteria by measuring their growth in $\mathrm{D}_{2} \mathrm{O}$ containing medium. Three types of bacteria (E. coli, $S$. aureus, and $P$. aeruginosa) were cultured at different concentrated $\mathrm{D}_{2} \mathrm{O}$ containing $\mathrm{LB}$ medium, and their growth were monitored with optical density (OD) measurement at 600 $\mathrm{nm}$ wavelength. We found that $\mathrm{D}_{2} \mathrm{O}$ concentration up to $100 \%$ did not show significant toxicity to the growth of E. coli and $S$. aureus, as indicated by the growth curve in $\mathrm{D}_{2} \mathrm{O}$ media of various concentrations (Figure 1a and $\mathbf{1 b}$ ). The growth of $P$. aeruginosa was initially slowed down in medium with $\mathrm{D}_{2} \mathrm{O}$ concentration of $70 \%$ and up, but eventually restored to normal growth after about $18 \mathrm{~h}$ for $\mathrm{D}_{2} \mathrm{O}$ concentration of $70 \%$ and $80 \%$, and about $22 \mathrm{~h}$ for $\mathrm{D}_{2} \mathrm{O}$ concentration of $100 \%$ (Figure 1c). Therefore, $\mathrm{D}_{2} \mathrm{O}$ concentration of $70 \%$ or lower in the medium does not induce significant toxicity to the bacteria.

Imaging metabolic incorporation of $\mathrm{D}_{2} \mathrm{O}$ in a single bacterium. We chose $70 \% \mathrm{D}_{2} \mathrm{O}$ containing $\mathrm{LB}$ medium to cultivate bacteria, and used $P$. aeruginosa to test whether the $\mathrm{D}_{2} \mathrm{O}$ metabolic incorporation in a single bacterium can be monitored by our SRS microscope. Spontaneous Raman spectra of bacteria showed a broad peak $\left(2070-2250 \mathrm{~cm}^{-1}\right)$ at C-D vibrational region for bacteria cultivated in the $\mathrm{D}_{2} \mathrm{O}$ containing medium for $2 \mathrm{~h}$ (Figure 2a), indicating $\mathrm{D}_{2} \mathrm{O}$ had been successfully utilized for biomolecule synthesis. For control, bacteria cultivated in normal medium did not have this peak at this region (Figure 2a). To image single bacterium, bacteria were further diluted and deposited on an agarose gel pad. By tuning the Raman shift to C-D region $\left(\sim 2162 \mathrm{~cm}^{-1}\right)$, a strong signal was observed for individual bacterium cultivated in $\mathrm{D}_{2} \mathrm{O}$ containing medium (Figure $\mathbf{2 b}$, right). As a control, no C-D signal was observed for bacteria cultured in normal medium (Figure 2b, left). The results were confirmed by SRS spectra (Figure 2c) obtained through temporal tuning of chirped pump and Stokes femtosecond pulses. Similar results were obtained on E. coli (Supporting Figure 1) and S. aureus (Supporting Figure 2).

In order to shorten the $\mathrm{D}_{2} \mathrm{O}$ culture time, we tested whether non-chirped femtosecond pulses can enhance the signal over the chirped picosecond pulses. Because the C-D vibration band is relatively broad with a width of $180 \mathrm{~cm}^{-1}$ (Figure 2c), we hypothesized that femtosecond SRS without chirping could significantly increase the signal to noise ratio (SNR). To test this, we cultivated $P$. aeruginosa in $70 \% \mathrm{D}_{2} \mathrm{O}$ containing $\mathrm{LB}$ medium for 30 minutes, and imaged them at $\sim 2162 \mathrm{~cm}^{-1}$ by chirped picosecond pulses and non-chirped femtosecond pulses, respectively (Figure 3a and 3c). The pump and Stokes powers were adjusted to make sure the same average pump and Stokes powers were used. The SNR of individual bacterium with picosecond and femtosecond SRS was 1.43 and 7.81, respectively, indicating $\sim 5.5$ times SNR improvement with femtosecond SRS over picosecond SRS (Figure 3b and 3d). This improvement is attributed to two factors. First, the C-D vibrational band is broad, and the femtosecond SRS can detect broader band signal than the chirped picosecond SRS. Second, the pulse chirping reduced the peak power of the pulses. Although the same average power was used at the sample, the reduced peak power decreased the signal level due to the nonlinear effect of SRS.

Time lapse measurement of $\mathrm{D}_{2} \mathrm{O}$ metabolic incorporation in a single bacterium. Next, we studied the time lapse of $\mathrm{D}_{2} \mathrm{O}$ metabolic activity in single $P$. aeruginosa with femtosecond SRS. The $P$. aeruginosa was cultivated in $70 \% \mathrm{D}_{2} \mathrm{O}$ containing LB medium for up to $3 \mathrm{~h}$. Figure $4 \mathrm{a}$ shows the SRS images of 
single $P$. aeruginosa at $2162 \mathrm{~cm}^{-1}$, C-D signal in individual $P$. aeruginosa can be observed after culture as short as 10 minutes. Statistical analysis showed that the average C-D signal intensity in individual bacterium increases with time, and saturates at $\sim 1.5 \mathrm{~h}$ (Figure $4 \mathbf{c}$ ), which is about three generations since the generation time of $P$. aeruginosa cultivated in LB medium is 24 -27 minutes $^{28}$. To view individual bacterium more clearly, the images in Figure 4a were further zoomed in (Figure $\mathbf{4 b}$ ). Interestingly, in the 10 minutes result, a stronger signal was observed in the cell periphery of bacterium (Figure $4 \mathbf{b}$ ), as indicated by the intensity plot over the bacteria (Figure 4d). In contrast, in and after 30 minutes, the signal intensity is stronger in the intracellular area (Figure $\mathbf{4 b}$ ), as indicated by the intensity plot over bacteria in the 30 minutes result (Figure $4 \mathbf{e}$ ). Collectively, these results suggest that $\mathrm{D}_{2} \mathrm{O}$ is initially used to synthesize cell membrane and/or cell wall in P. aeruginosa.

Rapid AST. To examine how antibiotics affect the metabolic incorporation of $\mathrm{D}_{2} \mathrm{O}$ in bacteria, and whether it can be used for rapid AST through SRS imaging, P. aeruginosa were cultivated in $70 \% \mathrm{D}_{2} \mathrm{O}$ containing $\mathrm{LB}$ medium, with the addition of 20 $\mu \mathrm{g} / \mathrm{ml}$ gentamicin or cefotaxime. The susceptibility of $P$. aeruginosa were pre-determined to be susceptible to gentamicin and resistant to cefotaxime at this concentration by the conventional culture-based microdilution method. SRS imaging at $\sim 2162 \mathrm{~cm}^{-1}$ showed that the C-D signal was significantly reduced after cultivation in $20 \mu \mathrm{g} / \mathrm{ml}$ gentamicin (Figure 5a), indicating that the metabolic activity of $\mathrm{D}_{2} \mathrm{O}$ in $P$. aeruginosa was inhibited by gentamicin. On contrary, $P$. aeruginosa cultivated in cefotaxime can be observed at $\sim 2162$ $\mathrm{cm}^{-1}$ SRS imaging at all time points, indicating active metabolic incorporation of $\mathrm{D}_{2} \mathrm{O}$ in $P$. aeruginosa when cultivated in cefotaxime. We observed that $P$. aeruginosa tends to form long rods when cultivated in cefotaxime (Figure 5b). This filamentary formation, which happens when Gram-negative bacteria are treated with $\beta$-lactam antibiotics, was also observed for $P$. aeruginosa treated with ceftazidime ${ }^{10}$.

To examine whether the $\mathrm{D}_{2} \mathrm{O}$ metabolic activity of bacteria can be used to rapidly differentiate the antibiotic susceptibility of bacteria, the average C-D signal intensity of bacteria was compared between three groups (Figure $\mathbf{5 c}-\mathbf{5 h}$ ), the control without antibiotics treatment (Figure 4a), treated with gentamicin (Figure 5a), and treated with cefotaxime (Figure AUTHOR INFORMATION

\section{Corresponding Authors}

*E-mail: jxcheng@bu.edu

\section{Author Contributions}

J.X.C, and W.H. conceived the idea. W.H. designed the experiment. W.H. and L.L. conducted the experiment. W.H. analyzed the data. W.H., and J.X.C. co-wrote the manuscript. All authors have given approval to the final version of the manuscript.

Notes

The authors declare no competing financial interests.

\section{ACKNOWLEDGMENT}

This work was supported by Keck Foundation Science \& Engineering Grant and R01GM118471 to JXC.

\section{REFERENCES}

5b). To separate the susceptible and resistant group, we determined a $65 \%$ line threshold, which is $65 \%$ the average $\mathrm{C}$ $\mathrm{D}$ intensity of bacteria in control, in all plots from 10 minutes to $3 \mathrm{~h}$ results (Figure $\mathbf{5 c}-\mathbf{5 h}$ ). This threshold can clearly divide the susceptible and resistant groups, the group treated with gentamicin was always below the threshold, and the group treated with cefotaxime was always above the threshold. Therefore, the susceptibility of $P$. aeruginosa to gentamicin and cefotaxime can be determined in as short as 10 minutes.

Metabolic activity based MIC determination. To test whether SRS metabolic imaging can quantitate the minimal inhibitory concentration (MIC) of antibiotics to bacteria, we cultivated $P$. aeruginosa in $70 \% \mathrm{D}_{2} \mathrm{O}$ containing $\mathrm{LB}$ medium for 1 hour with the addition of gentamicin with serial diluted concentration. SRS imaging at $2162 \mathrm{~cm}^{-1}$ showed that the $\mathrm{D}_{2} \mathrm{O}$ metabolic activity of $P$. aeruginosa was inhibited at $8 \mu \mathrm{g} / \mathrm{ml}$ or higher concentrated gentamicin cultivation (Figure 6a). For control, no C-D signal was observed for $P$. aeruginosa cultivated in normal LB medium. The average intensity of $P$. aeruginosa $\mathrm{C}-\mathrm{D}$ signal was plotted and compared. With the $65 \%$ intensity threshold, the metabolic activity based MIC was determined to be $8 \mu \mathrm{g} / \mathrm{ml}$ by the SRS-based $\mathrm{D}_{2} \mathrm{O}$ metabolic imaging method (Figure 6b). This value is consistent with the MIC determined by the broth dilution method.

\section{Conclusion}

We demonstrated rapid determination of the susceptibility of bacteria in 10 minutes by SRS imaging of the $\mathrm{D}_{2} \mathrm{O}$ metabolic incorporation in bacteria. Femtosecond SRS imaging can monitor $\mathrm{D}_{2} \mathrm{O}$ metabolism in bacteria at the single cell level with high signal to noise ratio. Antibiotics can inhibit the metabolic activity of $\mathrm{D}_{2} \mathrm{O}$ when the bacteria are susceptible to this antibiotic, and this inhibition can be observed after culture in $\mathrm{D}_{2} \mathrm{O}$ containing medium for 10 minutes. The metabolic activity based MIC can be quantitated by our method. Because water is an essential molecule for biosynthesis in bacteria, the SRSbased $\mathrm{D}_{2} \mathrm{O}$ metabolic imaging method has the potential to be generalized for rapid AST in various species including clinical samples.

(1) O'Neill, J. Tackling drug-resistant infections globally: final report and recommendations; The review on antimicrobial resistance, 2016.

(2) Sugden, R.; Kelly, R.; Davies, S. Nature microbiology 2016, 1, 16187.

(3) Kumar, A.; Roberts, D.; Wood, K. E.; Light, B.; Parrillo, J. E.; Sharma, S.; Suppes, R.; Feinstein, D.; Zanotti, S.; Taiberg, L. Critical care medicine 2006, 34, 1589-1596.

(4) Schoepp, N. G.; Schlappi, T. S.; Curtis, M. S.; Butkovich, S. S.; Miller, S.; Humphries, R. M.; Ismagilov, R. F. Science Translational Medicine 2017, 9, eaal3693.

(5) Murray, C.; Adeyiga, O.; Owsley, K.; Di Carlo, D. Lab on A Chip 2015, 15, 1226-1229.

(6) Hou, Z.; An, Y.; Hjort, K.; Sandegren, L.; Wu, Z. Lab on A Chip 2014, 14, 3409-3418.

(7) Choi, J.; Jung, Y.-G.; Kim, J.; Kim, S.; Jung, Y.; Na, H.; Kwon, S. Lab on a Chip 2013, 13, 280-287. 
bioRxiv preprint doi: https://doi.org/10.1101/496778; this version posted December 14, 2018. The copyright holder for this preprint (which was not certified by peer review) is the author/funder. All rights reserved. No reuse allowed without permission.

(8) Lu, Y.; Gao, J.; Zhang, D. D.; Gau, V.; Liao, J. C.; Wong, P. K. Analytical Chemistry 2013, 85, 3971-3976.

(9) Kim, S. C.; Cestellosblanco, S.; Inoue, K.; Zare, R. N. Antibiotics 2015, 4, 455-466.

(10) Choi, J.; Yoo, J.; Lee, M.; Kim, E.-G.; Lee, J. S.; Lee, S.; Joo, S.; Song, S. H.; Kim, E.-C.; Lee, J. C. Science translational medicine 2014, 6, 267ra174-267ra174.

(11) Baltekin, Ö.; Boucharin, A.; Tano, E.; Andersson, D. I.; Elf, J. Proceedings of the National Academy of Sciences 2017, 114, 91709175.

(12) Fredborg, M.; Andersen, K. R.; Jørgensen, E.; Droce, A.; Olesen, T.; Jensen, B. B.; Rosenvinge, F. S.; Sondergaard, T. E. Journal of Clinical Microbiology 2013, 51, 2047-2053.

(13) Schoepp, N. G.; Khorosheva, E. M.; Schlappi, T. S.; Curtis, M. S.; Humphries, R. M.; Hindler, J. A.; Ismagilov, R. F. Angewandte Chemie International Edition 2016, 55, 9557-9561.

(14) Barczak, A. K. Hung, D. T. Proceedings of the National Academy of Sciences 2012, 109, 6217-6222.

(15) Schröder, U.-C.; Beleites, C.; Assmann, C.; Glaser, U.; Hübner, U.; Pfister, W.; Fritzsche, W.; Popp, J.; Neugebauer, U. Scientific reports 2015, 5, 8217 .

(16) Tao, Y.; Wang, Y.; Huang, S.; Zhu, P.; Huang, W. E.; Ling, J.; $\mathrm{Xu}, \mathrm{J}$. Analytical Chemistry 2017, 89, 4108-4115.

(17) Syal, K.; Mo, M.; Yu, H.; Iriya, R.; Jing, W.; Sui, G.; Wang, S.; Grys, T. E.; Haydel, S. E.; Tao, N. Theranostics 2017, 7, 1795-1805.

(18) Hong, W.; Karanja, C. W.; Abutaleb, N. S.; Younis, W.; Zhang, X.; Seleem, M. N.; Cheng, J.-X. Analytical Chemistry 2018, 90, 3737-3743.

(19) Berry, D.; Mader, E.; Lee, T. K.; Woebken, D.; Wang, Y.; Zhu, D.; Palatinszky, M.; Schintlmeister, A.; Schmid, M. C.; Hanson, B. T. Proceedings of the National Academy of Sciences 2015, 112, E194E203.

(20) Fu, D.; Yu, Y.; Folick, A.; Currie, E.; Farese Jr, R. V.; Tsai, T.H.; Xie, X. S.; Wang, M. C. Journal of the American Chemical Society 2014, 136, 8820-8828.

(21) Freudiger, C. W.; Min, W.; Saar, B. G.; Lu, S.; Holtom, G. R.; He, C.; Tsai, J. C.; Kang, J. X.; Xie, X. S. Science 2008, 322, 1857 1861.

(22) Cheng, J.-X.; Xie, X. S. Science 2015, 350, aaa8870.

(23) Zhang, C.; Zhang, D.; Cheng, J.-X. Annual review of biomedical engineering 2015, 17, 415-445.

(24) Nanakumar, P.; Kovalev, A.; Volkmer, A. New Journal of Physics 2009, 11, 033026.

(25) Cheng, Q.; Wei, L.; Liu, Z.; Ni, N.; Sang, Z.; Zhu, B.; Xu, W.; Chen, M.; Miao, Y.; Chen, L.-Q. Nature Communications 2018, 9 , 2942.

(26) He, R.; Xu, Y.; Zhang, L.; Ma, S.; Wang, X.; Ye, D.; Ji, M. Optica 2017, 4, 44-47.

(27) Shi, L.; Zheng, C.; Shen, Y.; Chen, Z.; Silveira, E. S.; Zhang, L.; Wei, M.; Liu, C.; de Sena-Tomas, C.; Targoff, K.; Min, W. Nature Communications 2018, 9, 2995.
(28) Yang, L.; Haagensen, J. A.; Jelsbak, L.; Johansen, H. K.; Sternberg, C.; Høiby, N.; Molin, S. Journal of Bacteriology 2008, 190, 2767-2776. 

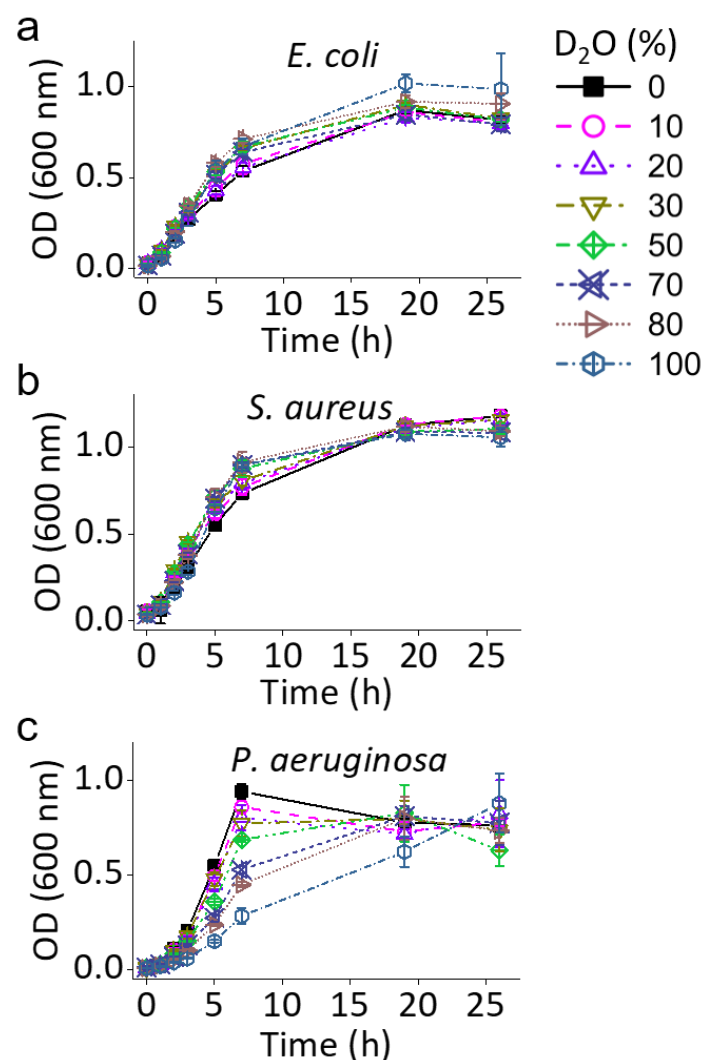

Figure 1. Testing of $\mathrm{D}_{2} \mathrm{O}$ toxicity to bacteria growth. Growth curve of E. coli (a), S. aureus (b) and P. aeruginosa (c) cultivated in LB medium with different $\mathrm{D}_{2} \mathrm{O}$ concentrations. 


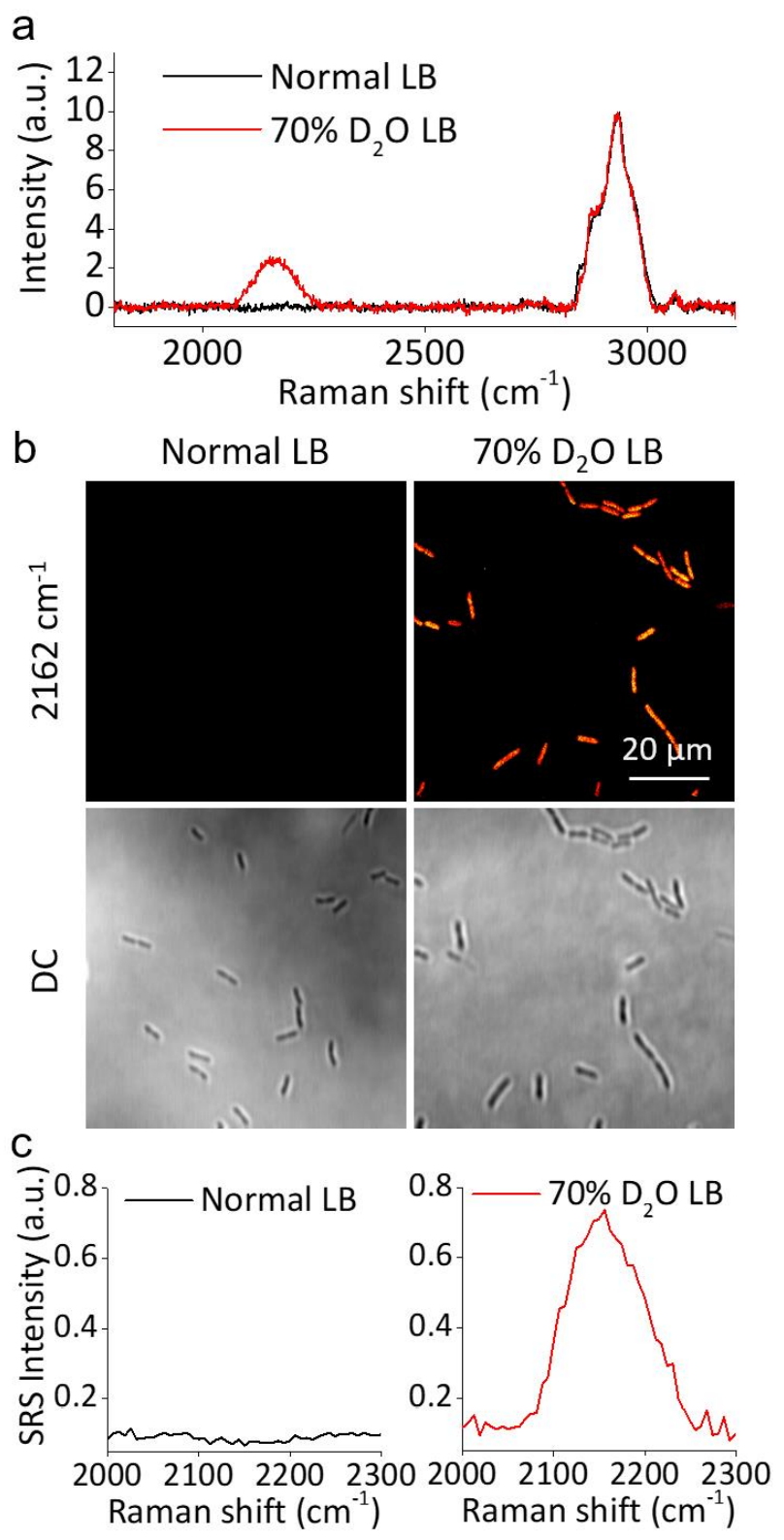

Figure 2. Biosynthesis in $P$. aeruginosa in $\mathrm{D}_{2} \mathrm{O}$ containing LB medium. a) Spontaneous Raman spectra of high-density $P$. aeruginosa cultivated in normal LB and $70 \% \mathrm{D}_{2} \mathrm{O}$ containing LB medium for $2 \mathrm{~h}$. b) SRS imaging at $\sim 2162 \mathrm{~cm}^{-1}$ and the corresponding transmission images of $P$. aeruginosa cultivated in normal and $70 \% \mathrm{D}_{2} \mathrm{O}$ containing LB medium for $2 \mathrm{~h}$. c) Corresponding SRS spectra of a single bacterium in (b). 


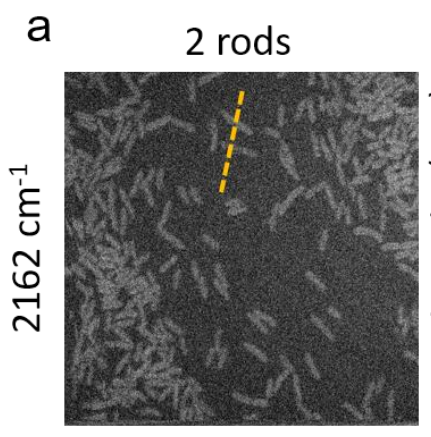

b
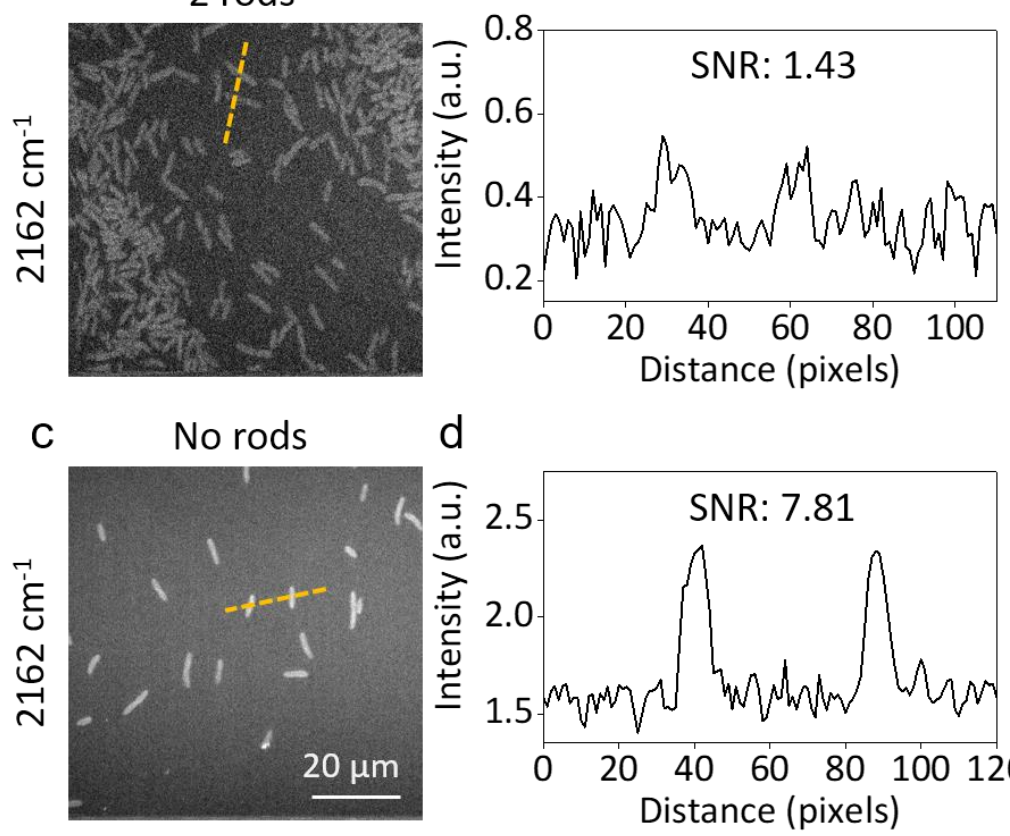

d

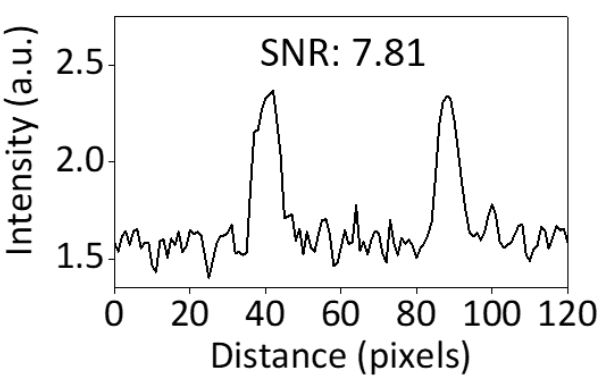

Figure 3. Femtosecond SRS improves SNR at C-D vibrational region over the chirped SRS. a) SRS imaging at $\sim 2162 \mathrm{~cm}^{-1}$ of $P$. aeruginosa cultivated in $70 \% \mathrm{D}_{2} \mathrm{O}$ containing LB medium for 30 minutes with picosecond pulses generated by chirping with two SF57 glass rods. b) Intensity plot of the orange line over bacteria in (a). c) SRS imaging at $\sim 2162 \mathrm{~cm}^{-1}$ of $P$. aeruginosa cultivated in $70 \% \mathrm{D}_{2} \mathrm{O}$ containing LB medium for 30 minutes with non-chirped femtosecond pulses. d) Intensity plot of the orange line over bacteria in (c). 
bioRxiv preprint doi: https://doi.org/10.1101/496778; this version posted December 14, 2018. The copyright holder for this preprint (which was not certified by peer review) is the author/funder. All rights reserved. No reuse allowed without permission.

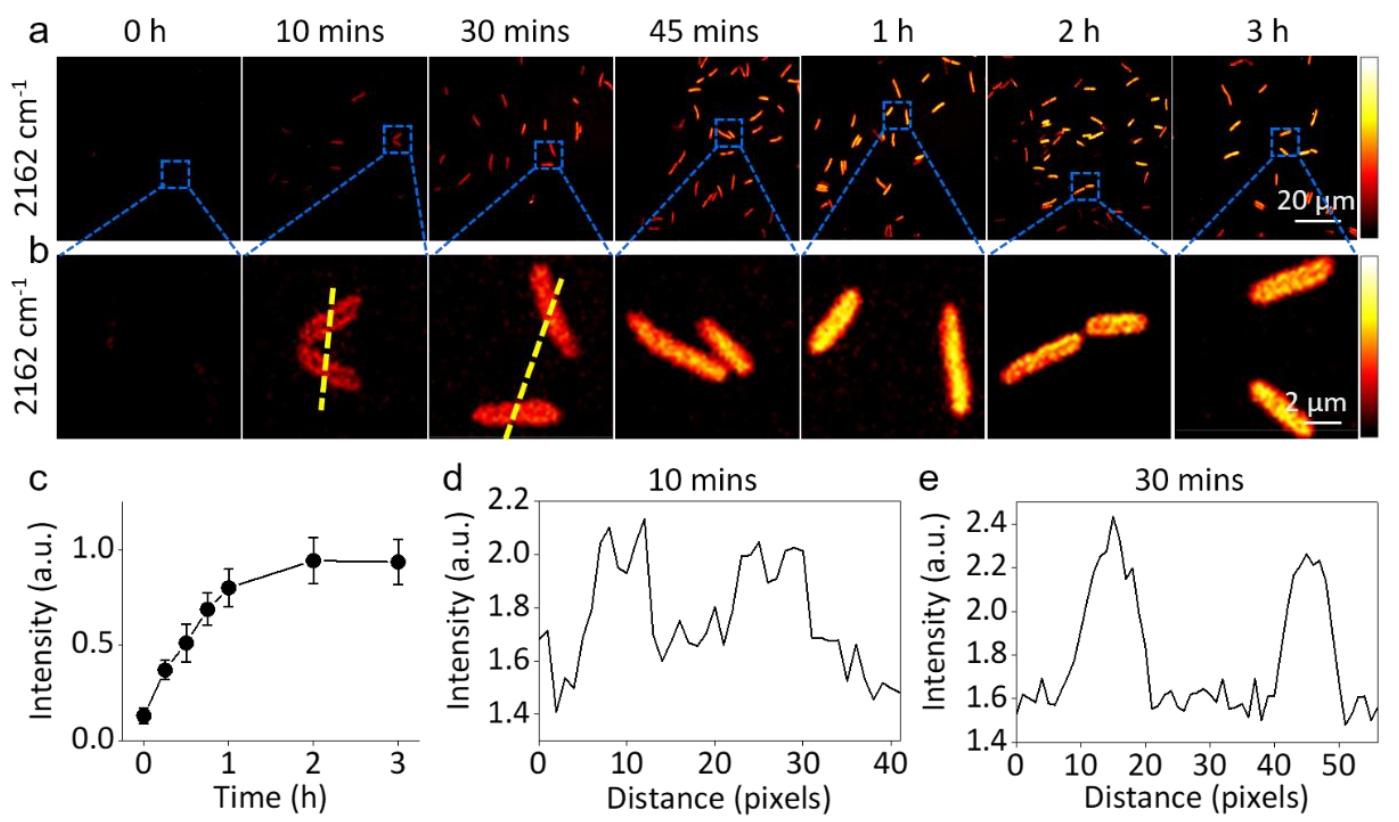

Figure 4. Time lapse SRS imaging of $\mathrm{D}_{2} \mathrm{O}$-based biosynthesis in P. aeruginosa. a) SRS imaging of $P$. aeruginosa cultivated in $70 \%$ D $\mathrm{D}_{2} \mathrm{O}$ containing LB medium from time 0 to $3 \mathrm{~h}$. b) Zoom in SRS imaging of individual $P$. aeruginosa in the rectangular square in (a). c) Growth of average SRS intensity of individual P. aeruginosa shown in panel a. Error bars indicate standard deviation $(\mathrm{N}>10)$. d) Intensity plot of the yellow line over bacteria from the 10 minutes result in (b). e) Intensity plot of the yellow line over bacteria from the 30 minutes result in (b). 

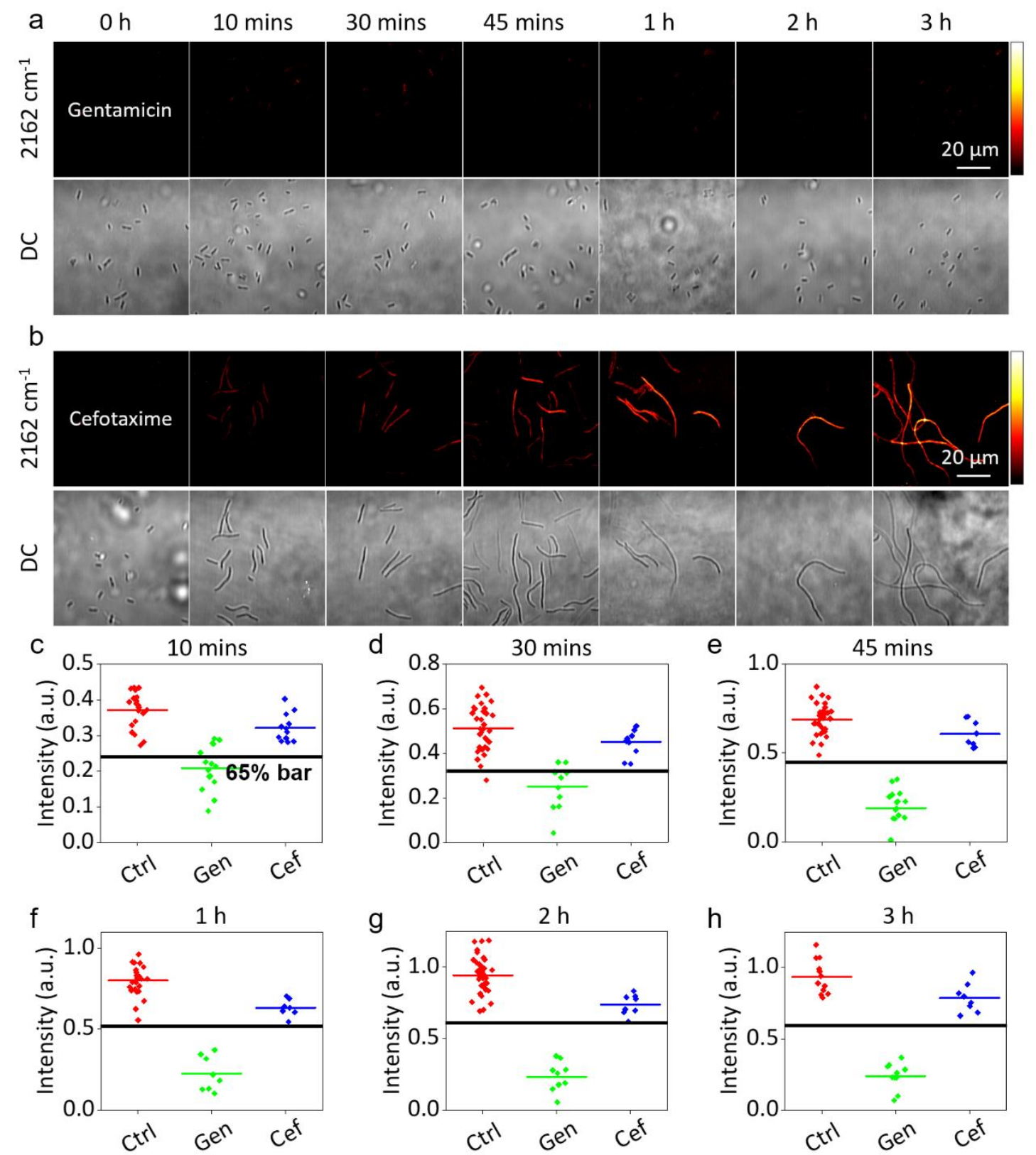

Figure 5. SRS-based antibiotic susceptibility testing of $P$. aeruginosa. a, b) C-D SRS imaging at $\sim 2162 \mathrm{~cm}^{-1}$ and transmission images of $P$. aeruginosa cultivated in $70 \% \mathrm{D}_{2} \mathrm{O}$ containing LB medium with the addition of $20 \mu \mathrm{g} / \mathrm{ml}$ gentamicin (a) or cefotaxime (b). c - f) Average C-D signal intensity of $P$ aeruginosa cultivated in $70 \% \mathrm{D}_{2} \mathrm{O}$ containing LB medium without antibiotic treatment (control), and with gentamicin or cefotaxime treatment for 10 minutes (c), 30 minutes (d), 45 minutes (e), $1 \mathrm{~h} \mathrm{(f),} 2 \mathrm{~h} \mathrm{(g)} \mathrm{or} 3 \mathrm{~h}$ (h). The colour bar indicates average C-D signal intensity of individual P. aeruginosa in each group. Black bar indicates the $65 \%$ intensity value of the average $P$. aeruginosa $\mathrm{C}-\mathrm{D}$ signal intensity in control. 
bioRxiv preprint doi: https://doi.org/10.1101/496778; this version posted December 14, 2018. The copyright holder for this preprint (which was not certified by peer review) is the author/funder. All rights reserved. No reuse allowed without permission.
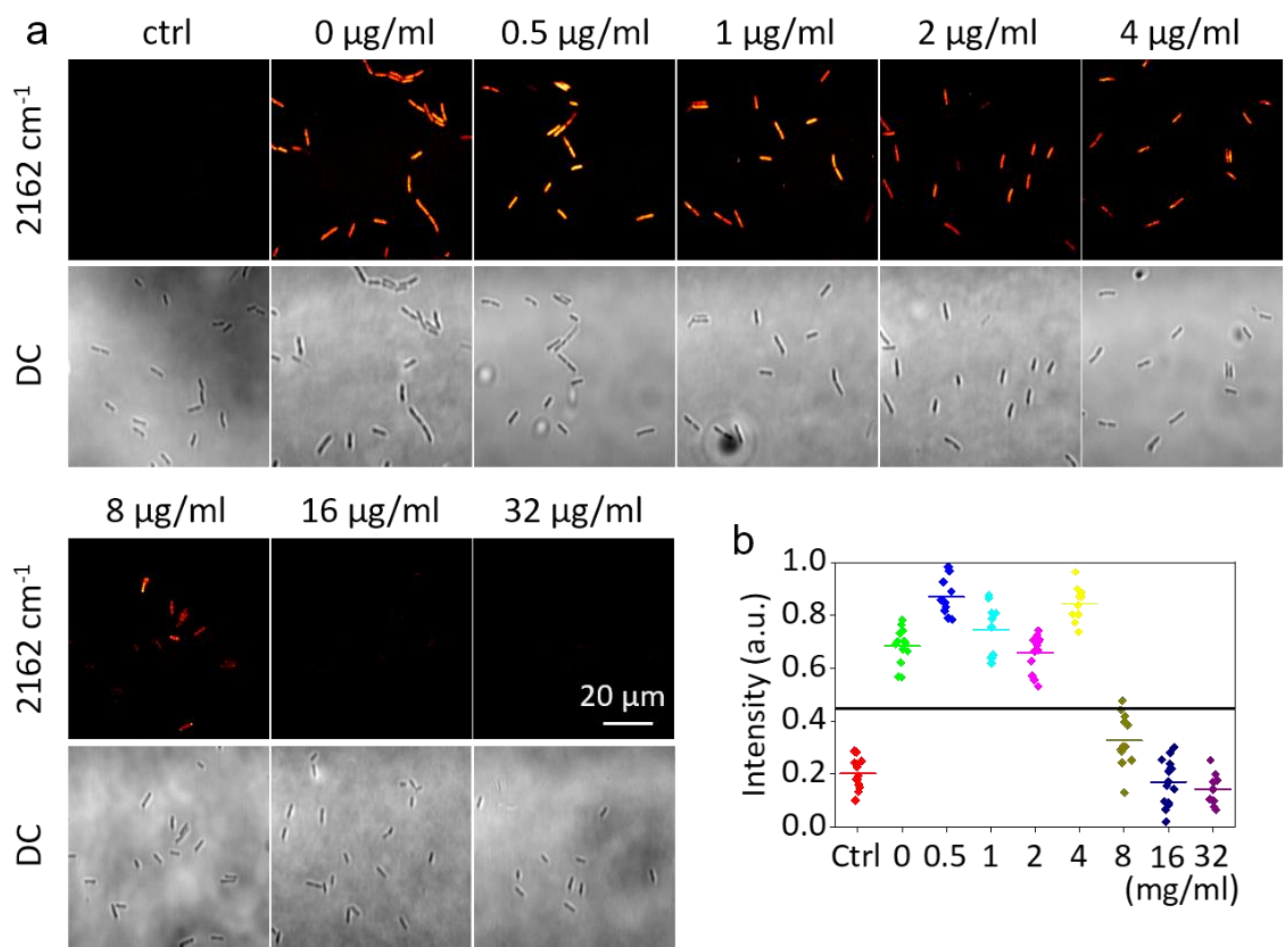

Figure 6. MIC determination of $P$. aeruginosa against gentamicin. a) C-D SRS imaging at $\sim 2162 \mathrm{~cm}^{-1}$ and transmission images of $P$. aeruginosa cultivated in normal $\mathrm{LB}$ (control) or $70 \% \mathrm{D}_{2} \mathrm{O}$ containing LB medium with the addition of different concentrated gentamicin. b) Average C-D signal intensity of individual P. aeruginosa in (a). Black bar indicates $65 \%$ intensity bar of the average SRS intensity of individual $P$. aeruginosa in $\mathrm{D}_{2} \mathrm{O}$ containing $\mathrm{LB}$ medium without treatment $(0 \mu \mathrm{g} / \mathrm{ml})$. 